\title{
Are Sovereign Ratings Biased Against Africa?
}

\author{
Colin Ellis ${ }^{1}$ \\ ${ }^{1}$ Visiting Professor, London South Bank University, United Kingdom \\ Correspondence: Colin Ellis, Visiting Professor, London South Bank University, United Kingdom.
}

Received: September 1, 2021

Accepted: December 14, $2021 \quad$ Available online: January 17, 2021

doi:10.11114/aef.v9i1.5453

URL: https://doi.org/10.11114/aef.v9i1.5453

\begin{abstract}
Credit rating agencies play a crucial role in financial markets, but are often criticized for particular judgements they make. With debt sustainability in Africa coming under pressure during the COVID-19 pandemic, some market commentators renewed concerns about anti-African bias in sovereign credit ratings. Using ratings data from one of the largest agencies, and economic and fiscal data independently sourced from the IMF, this article formally tests for anti-African bias in sovereign ratings. In doing so, it focuses purely on quantitative explanatory factors, given the potential for any bias in ratings to be reflected in implicit bias within qualitative judgements made by rating analysts. However, there is no statistical evidence of bias against African sovereign over the data sample, which runs from 2016. As such, any future improvements in African sovereign ratings are likely to reflect sustained improvements in economic and fiscal strength and other factors influencing creditworthiness, rather than the removal of any prejudice against this group.
\end{abstract}

Keywords: credit ratings, Africa, sovereigns, bias

\section{Introduction}

Access to funding is a key requirement for many developing economies, with international funding typically required to foster economic development via infrastructure, training or other means. But the risks associated with these foreign investments - as seen from the perspective of non-resident investors - are often substantial. As such, developing economies can face high funding costs.

One important set of actors in this framework are the credit rating agencies (CRAs). These agencies - especially the 'big three' of S\&P, Moody's and Fitch - provide external assessments of credit risk for investors, published as ratings. If CRAs' analysis is correct, lower-rated governments represent higher credit risk for investors and hence should be expected to face higher borrowing costs when issuing bonds.

The large CRAs have faced considereable criticism in recent years, notably for the role they played in the Global Financial Crisis of 2007/8 and associated spillovers to events such as the European sovereign debt crisis. Criticisms are often focused on particular types of ratings, such as structured finance transactions or credit ratings for countries, often called sovereigns by CRAs. Larger rating agencies' sovereign ratings typically cover over 100 countries around the world; but it is striking that many sovereign ratings on the African continent are in the lower part of global ratings scales. The role of CRAs in Africa was also thrown into the spotlight during the recent discussions on the global 'Debt Service Suspension Initiative' (DSSI) led by the World Bank and the International Monetary Fund (IMF). The DSSI arose from concerns about the sustainability of public sector debt burdens in many countries on the continent, and was designed to relieve some of that pressure. However, the DSSI also posed challenges for sovereign debt issuers, CRAs and creditors: in particular, proposals to suspend debt-service payments to private creditors would likely consistute a default under CRA definitions. Given the relatively low ratings that African countries had even prior to the onset of the COVID-19 pandemic, this has contributed to concerns that CRAs may be biased against African sovereigns - who in the absence of any bias would be expected to enjoy higher ratings, lower borrowing costs and hence brighter economic prospects.

In this paper, we test for this bias using the components of a detailed sovereign credit methodology, drawing data independently from non-CRA sources and assessing bias using a quantitative approach. We focus on Moody's rating approach given the greater transparency of its rating approach, and external ease of access to the underlying quantitative data.

Of course, this is not the first research paper to investigate the role and accuracy of credit ratings. Mora (2006) 
examines the role of CRAs in the East Asian crisis and finds that ratings are, if anything, sticky rather than procyclical, making it questionable whether ratings exacerbate the boom-bust cycle. Gültekin-Karakaș et al (2011) use a panel regression approach to investigate sovereign ratings, finding that developed countries have higher ratings even after macroeconomic fundamentals are accounted for. However, they note that analysts' qualitative judgements also matter, for instance around politics and other factors.

Ozturk (2014) builds on this by noting that bias can be accounted for by cross-country differences in institutional quality. Tennant and Tracey (2016) meanwhile model decisions by CRAs to keep ratings unchanged, finding that the threshold for upgrade is higher for poorer countries than for high-income countries. Further back, Cantor and Packer (1996) find positive correlations between economic development and credit ratings, after controlling for per capital GDP and other rating determinants.

Finally, more recently Tennant et al (2020) revisit vias against poor countries using a probit model that is based on a two-stage rating process, which splits out the propensity to change ratings from the direction and magnitude of the change. This is based on past work from Johnson (2004), whose findings are cited as evidence of a reduced desire for rating stability at the cusp of investment grade, relative to other rating levels. Tennant et al (op cit) again find evidence of bias, but it is questionable whether they have adequately captured the institutional quality issues and analytical judgements raised by Ozturk ( op cit) and Gültekin-Karakaș et al (op cit).

\section{Background and Statistical Methodology}

\subsection{Sovereign Credit Ratings: Approach and Outcomes}

The big three CRAs have similar approaches to assessing sovereign credit risk. In general, their published methodologies incorporate data on economic and fiscal outcomes and prospects, with significant qualitative overlays for concepts such as governance, risks and institutional frameworks. All of the big three CRAs publish their broad rating approaches; but among them, Moody's is arguably most transparent about its approach (Moody's, 2019). This greater transparency makes it the best candidate for testing any bias in its ratings.

Each of the big three publishes credit ratings for a range of sovereigns, ranging from AAA to D for S\&P and Fitch, and from Aaa to C for Moody's. The different ranges reflect the different rating scales that the CRAs use, with Moody's ratings speaking not just to the likelihood or probability of default (PD), but also to losses that investors suffer in the event of default (akin to a loss given default (LGD) perspective).

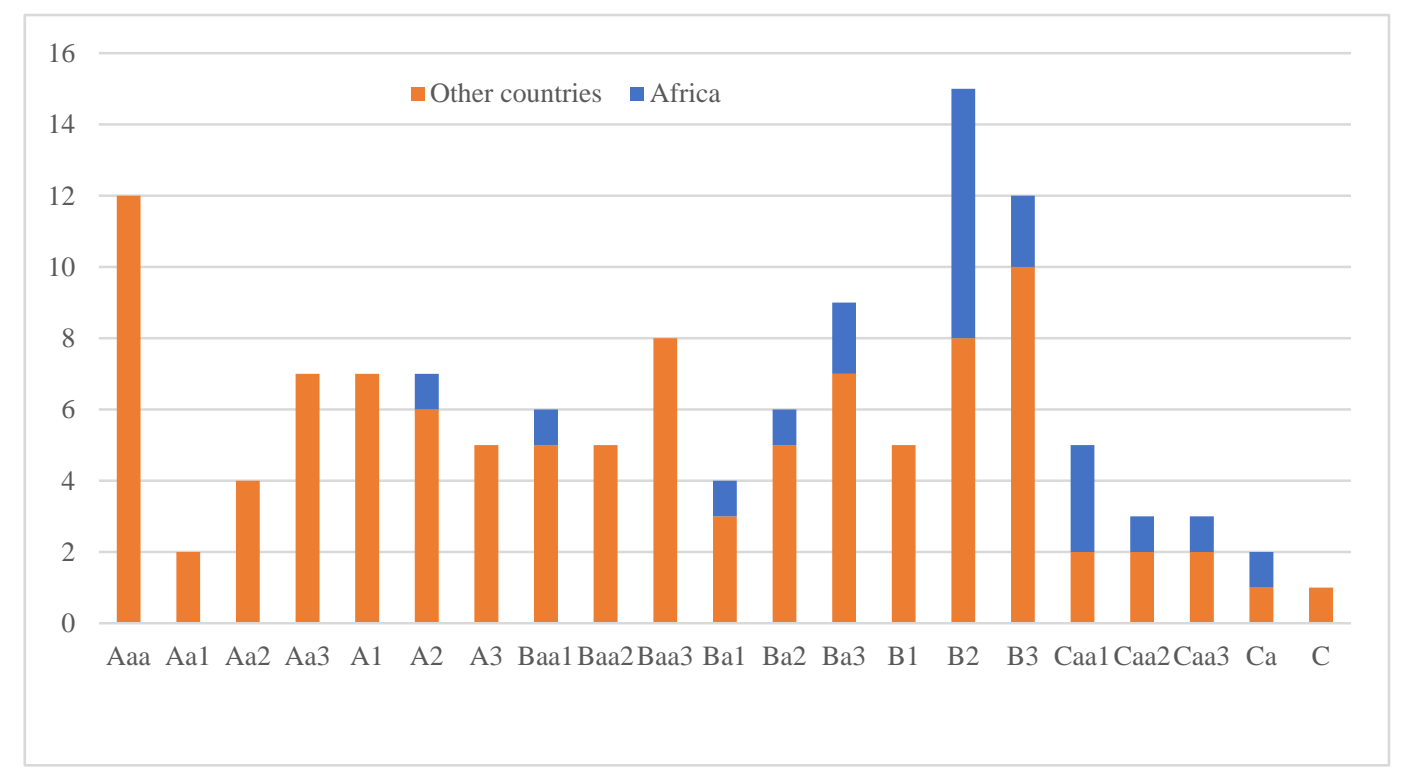

Figure 1. Moody's sovereign rating distribution at end-2020

Description: The Exhibit presents sovereign ratings from Moody's as of 31 December 2020. Source: Moody's.

As at the end of 2020, Moody's rated over 120 sovereign entities, using the whole breadth of its rating scale from Aaa (Norway, the US and others) to C (Lebanon). It is striking, however, that ratings for African countries - concentrated in sub-Saharan Africa (SSA) but also including Morocco, Tunisia and Egypt - were typically more concentrated in the lower part of the rating scale compared with the broader non-African distribution (Figure 1). Only two African 
sovereigns were rated as investment-grade credits: Botswana and Mauritius.

This raises an obvious question about whether Moody's is biased in its assessment of sovereign credit risk. It is possible that the differences in rating distribution between African and non-African countries represents underlying fundamental differences: but it is also possible it could represent bias, either implicit of otherwise. This is ultimately a testable hypothesis, which the remainder of this paper will examine.

\subsection{The Role of Implicit Bias and Need for a Purely Quantitative Approach}

Before starting any analysis, however, it is critical to first consider the form that any bias may take. As with other CRAs, Moody's sovereign rating approach incorporates qualitative factors - essentially akin to analyst judgement - alongside quantitative data. In factor, across its approach for generating 'scorecards' for sovereigns, two of the four key factors that Moody's identifies are primarily quantitatively driven, and two are essentially qualitative (Figure 2). Even after a scorecard-indicated outcome is constructed, rating analysts have considerable discretion in assigning a final rating, not least because the scorecard outcome is expressed as a range.

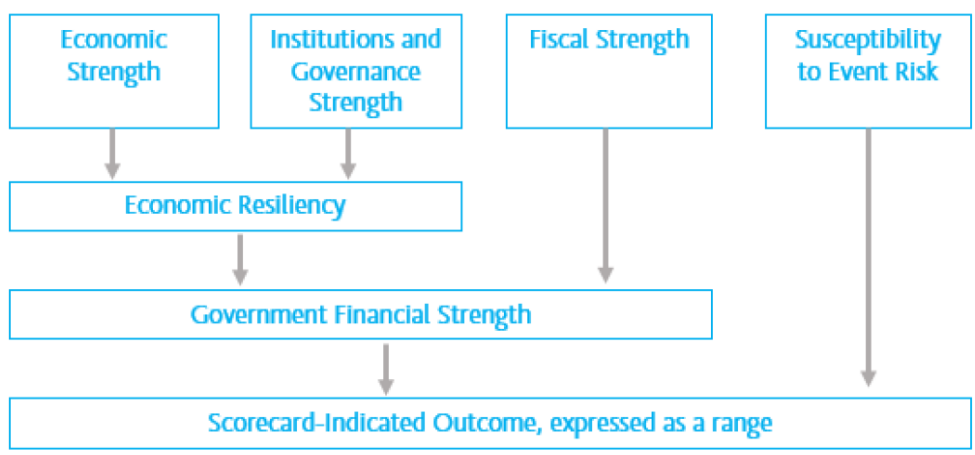

Figure 2. Moody's approach to sovereign rating scorecards

Source: Moody’s (2019).

The presence of this discretion, and more generally any qualitative judgements, complicates our ability to test for bias. Technically, it would be possible for Moody's to 'hide' any overt bias by assigning worse qualitative assessments - in a credit risk sense - for some countries than others. Indeed, it would be possible to construct a sovereign rating methodology that implicitly incorporated this bias, for instance by assigning lower 'institutional and governance' factor scores to African countries than for other countries. And given the entirely qualitative nature of these scores, it is impossible - given publicly available data, at least - to identify how much of any qualitative judgement reflects 'true' conditions versus conscious or unconscious bias.

Put another way, when testing for bias we cannot simply accept the qualitative judgements of the rating agency, because by definition these judgements will be subjective and that subjectivity could implicitly incorporate bias. Moody's has one global sovereign rating approach, so it is already apparent that there must be a combination of the four key factors that yields the distribution shown in Exhibit 1. This means that testing for bias while incorporating these qualitative and subjective judgements will not be meaningful; statistical testing could suggest no evidence of bias because it is already present in the 'explanatory' variables any testing would account for.

As such, the only unadulterated manner in which we can test for bias is to ignore qualitative judgements completely and focus on purely quantitative data metrics. Furthermore, we should ideally obtain these quantitative data not from the rating agency, but from a trusted third-party source. 
Table 1. Quantitative economic and fiscal data used in Moody's sovereign rating analysis

\begin{tabular}{|l|l|}
\hline \multicolumn{2}{|l|}{ Economic Strength Factor } \\
\hline & Average Real GDP Growth $(t-4$ to $t+5)$ \\
\hline & Volatility in Real GDP Growth $(t-9$ to $t)$ \\
\hline & Nominal GDP (US\$ bn, @ t) \\
\hline & GDP per Capita (PPP, Int. USD, @ $t)$ \\
\hline Fiscal Strength Factor \\
\hline & General Government Debt / GDP (@ t) \\
\hline & General Government Debt / Revenue (@ t) \\
\hline & General Government Interest Payments / Revenue (@ $t)$ \\
\hline & General Government Interest Payments / GDP (@ t $)$ \\
\hline
\end{tabular}

Source: Moody's (2019). 't' values refer to calendar year timings.

Happily, two factors enable this approach to be pursued. First, Moody's is - as noted earlier - relatively transparent among the 'big three' CRAs in its rating methodology. Thanks to this transparency, it is relatively simple to identify the key quantitative data series that are used in its rating process. These are summarised in Table 1: the data feed into Moody's assessments of economic strength (sometimes called Factor 1) and fiscal strength (Factor 3).

Second, the data series listed above are relatively simply to obtain from the IMF's World Economic Outlook database. The IMF is globally recognised as placing a high emphasis on the completeness and accuracy of data; so it can act as a trusted source for the data series listed in Exhibit 3.

This then allows us to pursue a purely quantitative test of bias in Moody's sovereign ratings. By mapping its distribution of sovereign ratings against the raw quantitative data that Moody's itself purports to use, we can examine whether these data align consistently with its ratings, or whether there is any sign of bias. Given that this is prior to any qualitative and subjective judgement that Moody's then adds in its approach and assessments, it offers the cleanest test for bias in sovereign ratings.

Before proceeding to the analysis, it is useful to first consider the quantitative metrices that Moody's incorporates in its rating methodology. Some variables are unsurprising; for instance, a higher debt-GDP ratio is often associated with greater credit risk, other things being equal. But the level of detail across similar variables is striking. Average growth over a number of years is probably meant as a proxy for trend growth, albeit with short-sample bias given only ten years are used in the calculation. But the total size of the economy in nominal terms at market exchange rates, and purchasing price parity (PPP) estimates of GDP per capita also offer useful information beyond pure growth estimates. The former reflects an assessment that size does ultimately matter; while the latter is taken as a proxy for comparing average income levels across countries. Interestingly, growth volatility - the second moment of GDP - is a separate factor as well. While the pace of growth matters, Moody's also believes that high volatility in growth (as measured by the standard deviation) undermines wealth creation and competitiveness. In turn this can reduce an economy's ability to withstand shocks, and a government's capacity to pursue stable, predictable policies.

\subsection{Data Gathering}

Moody's credit ratings are continually updated, reflecting both events external to the rating agency and internal judgements and discussions. As such, it is best to consider the rating distribution as an evolving mechanism, rather than a fixed-point outcome. This could lead to a potentially complex testing approach; but it also allows for time-consistency concerns to be addressed.

In order to balance these issues, this analysis focuses on the end-year distribution of sovereign ratings for each year from 2016 until 2020. This essentially focuses on a single snapshot for each year; but at the same time allows the distribution to shift over time (Figure 3). 


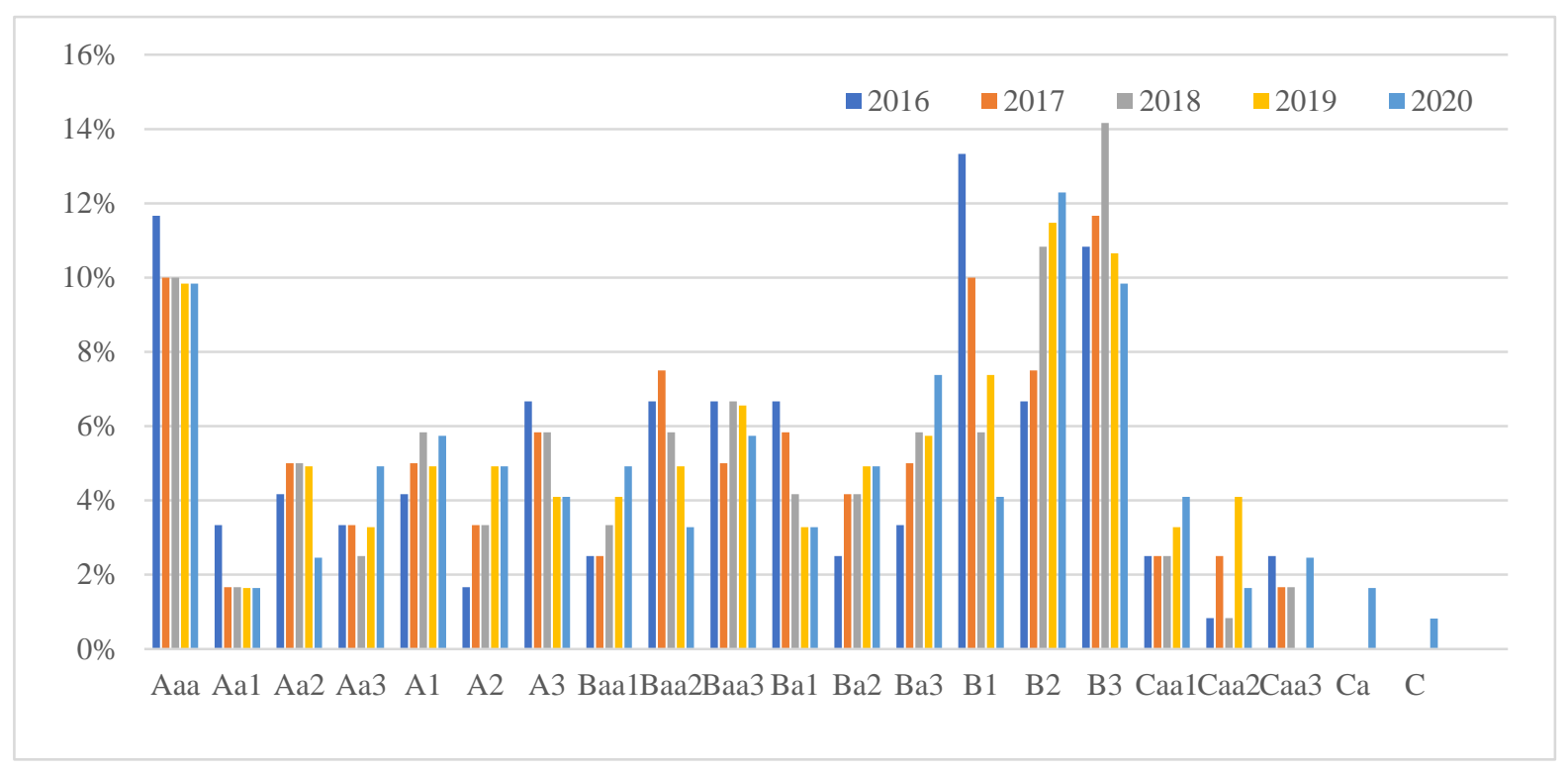

Figure 3. Moody's sovereign rating distribution over time

Source: Moody's.

For each of the five points-in-time, data were collected from the IMF to match the information available to rating analysts at that time. Most of the data used by Moody's are backward-looking in nature; but the average growth metric spans both the recent past and expected outcomes over the following five years. For simplicity, these forecasts were proxied by actual outcomes, and the IMF's own forecasts for later years. While this introduces some errors given Moody's forecasts will not have been completely accurate (nor identical to those of the IMF), this type of error should be reasonably evenly distributed across countries (conditional on underlying uncertainties). The one instance where it may be more concentrated is likely to be for 2020, given the COVID-19 pandemic and varying responses from governments around the world. Another useful aspect of focusing on the end-year rating distributions is that it allows us to compare outlier events (like 2020) with other points in time.

One important point is that we matched all construction of the quantitative data, as best as was possible, to the form of the data described in Moody's methodology (Table 1). If our analysis it going to explore bias cleanly, we cannot use different data formations from those used by the rating agency. This also encompasses the choice of variables we include in the analysis. While it would be simple to incorporate other quantitative data series into this analysis to see if they 'add value' to ratings beyond that provided by the data Moody's cites, that is not focus of this paper. Including extra variables in our analysis could potentially affect the empirical assessment of any bias in African ratings, which is the key focus of this piece. As such, we deliberately only include variables in our analysis that Moody's also uses.

Having matched the IMF data with Moody's rating coverage, in total we obtained rating and quantitative economic and fiscal data for 122 countries across the 2016 to 2020 period. Of these, 21 countries are from the African continent. This represents a sizeable sample on which to base our analysis.

\section{Quantitative Results}

Having gathered both ratings data for sovereigns from Moody's, and IMF-sourced economic and financial data that are considered in Moody's sovereign rating process, we were able to pursue formal quantitative testing of any bias in the sovereign ratings.

In order to test for bias, we first have to specify the correct type of modelling approach. Given the quantitative explanatory data, at first glance it may seem simple to model the ratings using ordinary least squares (OLS) regressions, and to include a dummy variable for African sovereigns. However, this would be inappropriate given the nature of the ratings data.

In particular, ratings are rank orderings of credit risk on a 21-point scale. As such, the ratings cannot be treated as a continuous variable but instead should be modelled as an ordered dependent variable. As first outlined by Aitchison and Silvey (1957), it is possible to estimate models for these types of data using a variety of assumptions about the underlying error distribution. We adopt an ordered probit approach here. To start with, we focus on cross-sectional estimations; it is notable that we only have five years of data, but by pursuing an explicitly cross-sectional approach it is 
readily apparent that we have more than enough degrees of freedom to provide consistent estimates on an individual year basis.

Essentially, the test of bias is simple. We model year-end ratings in each year using the IMF quantitative data as cross-sectional regressors, and include a dummy variable that takes the value of one for African countries, and zero otherwise. We estimate five separate models - one for each year - and test for the significance of the dummy variable in each instance. Estimation results from these five separate models are shown in Table 2.

Table 2. Results from individual-year probit estimation analysis to test for bias

\begin{tabular}{|c|c|c|c|c|c|c|c|c|c|c|}
\hline & 2016 & & 2017 & & 2018 & & 2019 & & 2020 & \\
\hline & Coefficient & P-value & Coefficient & P-value & Coefficient & P-value & Coefficient & P-value & Coefficient & P-value \\
\hline Average growth & -0.076 & 0.212 & -0.039 & 0.520 & -0.035 & 0.568 & -0.044 & 0.491 & 0.063 & 0.330 \\
\hline Volatility of growth & -0.259 & 0.000 & -0.367 & 0.000 & -0.380 & 0.000 & -0.608 & 0.000 & -0.175 & 0.018 \\
\hline Per capita income (PPP) & 0.000 & 0.000 & 0.000 & 0.000 & 0.000 & 0.000 & 0.000 & 0.000 & 0.000 & 0.000 \\
\hline \$ economy size & 0.000 & 0.000 & 0.000 & 0.000 & 0.000 & 0.000 & 0.000 & 0.000 & 0.000 & 0.000 \\
\hline Debt / GDP & -0.013 & 0.144 & -0.027 & 0.003 & -0.028 & 0.003 & -0.024 & 0.004 & -0.026 & 0.001 \\
\hline Debt / revenues & 0.000 & 0.750 & 0.000 & 0.316 & 0.000 & 0.134 & 0.000 & 0.163 & 0.000 & 0.013 \\
\hline Interest payments / revenues & 0.001 & 0.754 & -0.001 & 0.779 & -0.002 & 0.553 & -0.003 & 0.332 & -0.002 & 0.427 \\
\hline Interest payments / GDP & -0.128 & 0.386 & -0.062 & 0.656 & -0.067 & 0.640 & -0.042 & 0.748 & 0.035 & 0.779 \\
\hline Africa dummy & 0.258 & 0.366 & 0.310 & 0.286 & 0.156 & 0.600 & 0.385 & 0.202 & 0.050 & 0.862 \\
\hline Pseudo- $\mathrm{R}^{2}$ & 0.242 & n.a. & 0.289 & n.a. & 0.291 & n.a. & 0.315 & n.a. & 0.253 & n.a. \\
\hline LR statistic & 159.409 & 0.000 & 194.506 & 0.000 & 192.686 & 0.000 & 214.485 & 0.000 & 176.992 & 0.000 \\
\hline
\end{tabular}

Discription: Estimation results from cross-sectional ordered probit regressions of sovereign ratings on explanatory variables shown. A p-value of below 0.05 indicates statistical significance at the $5 \%$ level.

Using the appropriate ordered probit modelling approach, the dummy variable for African sovereigns is insignificant in each and every year between 2016 and 2020. Or in other words, there is no sign of systematic bias against countries in Africa. The pseudo- $\mathrm{R}^{2}$ are broadly comparable with results for other ordered probit regressions, and the likelihood ratio (LR) statistics are highly significant in all instances, indicating that the models do offer a statistically significant description of the ratings data.

The quantitative variables included in the regressions are generally significant, but not always. Similarly, the signs of the regressions are not always what might have been expected. The credit rating nomenclature we are using runs from 1 (lowest) to 21 (highest). So some variables have the sign that might be broadly expected: higher debt-GDP and interest payments to GDP lower the modelled rating, and per capita income and the size of the economy increase it, with growth volatility weighing on the rating. But for some years growth itself has a negative coefficient; happily, this variable is insignificant in the modelling.

Broadly speaking, the variables linked with Economic Strength are more consistently statistically significant than variables linked with Fiscal Strength. As noted earlier, growth volatility, the nominal size of the economy and per capita incomes are consistently significant and correctly signed for the former; but for the latter fewer variables are consistently significant, with debt-GDP ratios being most notable. Most importantly, across all five regressions there is no evidence of systematic bias for African ratings compared with those of other countries.

As a further cross-check, a sixth regression was estimated that used the entire dataset in a panel regression. In doing so, we combine the cross-sectional data across the five separate years into one single model. In essence, this is a constrained regression model where we force coefficients to remain constant across the different years of the panel; as such, it is arguably a means of cross-checking the results already presented herein. Results from this panel regression are shown in Table 3 below. 
Table 3. Results from panel estimation to test for bias

\begin{tabular}{lcc} 
& Coefficient & P-value \\
Average growth & -0.012 & 0.642 \\
Volatility of growth & -0.264 & 0.000 \\
Per capita income (PPP) & 0.000 & 0.000 \\
\$ economy size & 0.000 & 0.000 \\
& & \\
Debt / GDP & -0.020 & 0.000 \\
Debt / revenues & 0.000 & 0.015 \\
Interest payments / revenues & -0.001 & 0.459 \\
Interest payments / GDP & -0.064 & 0.278 \\
& & \\
Africa dummy & 0.163 & 0.204 \\
\hline & & \\
Pseudo-R & & \\
LR statistic & 0.254 & $n . a$.
\end{tabular}

Discription: Estimation results from panel ordered probit regressions of sovereign ratings on explanatory variables shown from 2016 to 2020 . A p-value of below 0.05 indicates statistical significance at the $5 \%$ level.

The results shown in Table 3 are consistent with the results from the individual cross-sectional regressions. Growth volatility, per capital incomes and nominal economy size are all statistically significant among the economic data, while the debt-GDP ratio is the most significant indicator among the fiscal data series. The fit of the model is broadly comparable with that of the individual regressions. And, importantly, the dummy variable testing for bias in African ratings is again statistically insignificant.

While this does not preclude the absolute presence of bias - the quantitative data are not the only inputs Moody's considers, and qualitative judgements could include subjective bias - it does suggest that the independent quantitative data alone can capture as much of the rating distribution as possible. That is not to say that the quantitative metrics can explain all of the variation in the distribution of sovereign ratings; but adding an African identifier does not improve the modelling outcome.

\section{Discussion and Conclusions}

Credit rating agencies often face criticisms from market participants and commentators, notably for their role in the 2007/8 Global Financial Crisis. Given the critical role that external financing plays for many developing nations, and the need to attract external capital, the role of CRAs for emerging market countries is also frequently under scrutiny. Often CRAs are seen as the 'gatekeepers' to global capital markets for smaller, poorer sovereigns, and they are criticized when downgrades occur. In part, this is the nature of the role that CRAs play: they are there to assess credit risk without fear or favour, and weaker, poorer countries typically have a greater risk of default than richer economies. But there are also sometimes concerns that CRAs can be biased against particular groups of companies in their credit analysis.

This paper has examined these concerns, focusing on African sovereigns given the credit stresses there and official sector recognition of these, via the recent DSSI from the World Bank and IMF. In doing so, we have deliberately excluded all qualitative judgements from our analysis, as that would allow any bias already implicit in these judgements to account for any bias in final ratings. Instead, the cross-section of ratings at the end of each year were modelled against purely quantitative data from a trusted third-party source; and this model was used to test for bias in Moody's sovereign ratings against African countries.

Results from the quantitative analysis are clear and unambiguous. For each year from 2016 to 2020, there is no statistically significant sign of anti-African bias in the distribution of Moody's ratings, once quantitative factors such as growth, debt and volatility are accounted for. Interestingly, not all of the quantitative factors listed by Moody's are statistically significant or consistent in the cross-sectional results: in part, this may speak to the considerable flexibility that rating analysts enjoy in forming their credit opinions. But the critical result from this analysis is that there is no evidence of bias against African countries. As such, while stronger credit ratings would potentially lead to lower borrowing costs and brighter economic prospects for African sovereigns, obtaining such higher ratings is only likely via sustained improvements in economic and fiscal strength and other factors influencing creditworthiness. 


\section{References}

Afonso, A., Gomes, P., \& Rother, P. (2011). Short and long-run determinants of sovereign debt credit ratings. International Journal of Finance an Economics, 16, 1-15. https://doi.org/10.1002/ijfe.416

Aitchison, J., \& Silvey, S. D. (1957). The generalization of probit analysis to the case of multiple responses. Biometrika, 44, 131-40. https://doi.org/10.2307/2333245

Cantor, R., \& Packer, F. (1996). Determinants and impact of sovereign credit ratings. The Journal of Fixed Income, Winter, 6(3), 76-91. https://doi.org/10.3905/jfi.1996.408185.

Gültekin-Karakaş, D., Hisarciklilar, M., \& Öztürk, H. (2011). Sovereign risk ratings: Biased toward developed countries? Emerging Markets Finance \& Trade, 47(2), 69-87. https://doi.org/10.2753/REE1540-496X4703S204 https://doi.org/10.1016/j.najef.2018.11.006

Johnson, R. (2004). Rating agency actions around the investment-grade boundary. The Journal of Fixed Income, 13(4), 25-37. https://doi.org/10.3905/jfi.2004.391025

Moody's. (2019). Sovereign Ratings Methodology, 25 November. Retrieved from www.moodys.com

Mora, N. (2006). Sovereign credit ratings: guilty beyond reasonable doubt? Journal of Banking and Finance, 30, 2041-2062. https://doi.org/10.1016/j.jbankfin.2005.05.023

Ozturk, H. (2014). The origin of bias in sovereign credit ratings: Reconciling agency views with institutional quality. The Journal of Developing Areas, 48(4), 161-188. https://doi.org/10.1353/jda.2014.0066

Tennant, D., \& Tracey, M. R. (2016). Sovereign debt and credit rating bias. New York, NY: Palgrave Pivot. https://doi.org/10.1057/9781137391506

Tennant, D., Tracey, M. R., \& King, D. W. (2020). Sovereign credit rating: Evidence of bias against poor countries. North American Journal of Economics and Finance, 51, January. https://doi.org/10.1016/j.najef.2018.11.006

\section{Copyrights}

Copyright for this article is retained by the author(s), with first publication rights granted to the journal.

This is an open-access article distributed under the terms and conditions of the Creative Commons Attribution license which permits unrestricted use, distribution, and reproduction in any medium, provided the original work is properly cited. 